\title{
Picogram Level Quantification of Grazoprevir and Elbasvir with Deuterated Internal Standards in Human Plasma Samples by LC-ESI-MS/MS
}

\author{
Haritha Potluri ${ }^{*}$, Sreenivasa Rao Battula ${ }^{2}$, Sunandamma Yeturu ${ }^{3}$ \\ 'Department of Chemistry, JNTUK, Kakinada-533003, India \\ ${ }^{2}$ Department of Chemistry, GITAM University, Visakhapatnam-530045, India \\ ${ }^{3}$ Department of Chemistry, Acharya Nagarjuna University, Nagarjuna nagar-522510, India
}

\begin{abstract}
A fixed oral dose combination of grazoprevir and elbasvir is used for the treatment of patients with genotypes $1 \& 4 \mathrm{HCV}$ infections. In this manuscript, authors developed a simple, sensitive and specific liquid chromatography-tandem mass spectrometry (LC-MS/MS) method used for quantification of grazoprevir and elbasvir in human plasma. Agilent TC-C18, $4.6 \times 75 \mathrm{~mm}, 3.5 \mu \mathrm{m}, 80 \AA$ column, and $5 \mathrm{mM}$ ammonium acetate: acetonitrile $(20: 80 \mathrm{v} / \mathrm{v})$ mobilephase was used for Chromatographic separation. MRM positive mode was used to detect the grazoprevir and elbasvir at $\mathrm{m} / \mathrm{z}$ 767.3/553.2, 883.4/656.3 respectively. Liquid-liquid extraction was employed in the extraction of analytes and internal standard from human plasma. This method is validated over a linear concentration range of 50.0 - $10000.0 \mathrm{pg} / \mathrm{ml}$ for grazoprevir and elbasvir. Calibration functions, lower limit of quantitation (LLOQ), stability, intra and inter-day reproducibility, accuracy, and recovery are estimated. Both drugs were stable in plasma samples. This method was free from matrix effects and any abnormal ionization.
\end{abstract}

Key words: LC-ESI-MS/MS, Grazoprevir, Elbasvir, Human plasma, Bioanalytical.

\section{INTRODUCTION}

Hepatitis $\mathrm{C}$ infection is a major issue concerned to global health. According to the centers for disease control and prevention estimates, of the people infected with liver diseases, about 3 million deaths occur worldwide each year due to hepatitis $C$ virus (HCV) related causes. ${ }^{1,2}$

Treatment options for patients with hepatitis C infection and stage 4 to 5 chronic kidney disease remain suboptimum. Approved all oral therapies are not ideal regimens because they contain drugs whose metabolites are cleared by the kidney or because they need co-ordination with ribavirin, which is associated with anaemia. ${ }^{3}$

Zepatier (marketed by Merck and co. inc, New jersey) is a fixed dose combination tablet (single dose once daily) containing grazoprevir- $100 \mathrm{mg}$ (GP) and elbasvir- $50 \mathrm{mg}$ (ES) was approved by FDA (Jan 28, 2016) to market globally. It was used for treatment of patients with genotypes 1 and $4 \mathrm{HCV}$ infections with or without use of ribavarin. The safety and efficacy of zepatier was evaluated in clinical trials of 1,373 participants with chronic HCV genotype 1 or 4 infections with or without cirrhosis. ${ }^{3,4}$

Grazoprevir (Figure 1) is a hepatitis $C$ virus NS3/4Aproteaseinhibitor.TheIUPACname for grazoprevir is $(1 \mathrm{aR}, 5 \mathrm{~S}, 8 \mathrm{~S}, 10 \mathrm{R}, 22 \mathrm{aR})$ $\mathrm{N}-[(1 \mathrm{R}, 2 \mathrm{~S})-1-[($ Cyclopropylsulfonamido $)$ carbonyl]-2-ethenylcyclopropyl]-14methoxy-5-(2-methylpropan-2-yl)-3,6-dio xo1, $1 \mathrm{a}, 3,4,5,6,9,10,18,19,20,21,22,22 \mathrm{a}-$
Submission Date : 05-06-2016 Revision Date : 31-08-2016 Accepted Date : :14-09-2016

DOI: 10.5530/ijper.50.4.14 Correspondence:

P Haritha*

Department of Chemistry, JNTUK, Kakinada-533003, India

E-mail: haritha.potluri@ gmail.com Ph.no: 918674-241854

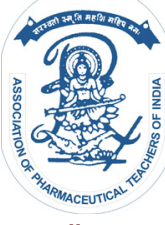

www.ijper.org 
tetradecahydro-8H-7,10-methanocyclopropa $(18,19)$ $(1,10,3,6)$ dioxadiazacyclononadecino $(11,12-b)$ quinoxaline-8-carboxamide.It has a molecular formula of $\mathrm{C}_{38} \mathrm{H}_{50} \mathrm{~N}_{6} \mathrm{O}_{9} \mathrm{~S}$ and a molecular weight of $766.90 . .^{5}$

Elbasvir (Figure 1) is an HCV NS5A inhibitor. ${ }^{6}$ The IUPAC name for elbasvir is Dimethyl N,N'-([(6S)6-phenylindolo(1,2-c) (1,3)benzoxazine-3,10-diyl] bis $\{1 \mathrm{H}$-imidazole-5,2-diyl-(2S)-pyrrolidine-2,1diyl[(2S)-3-methyl-1-oxobutane-1,2-diyl]\})dicarbamate. It has a molecular formula of $\mathrm{C}_{49} \mathrm{H}_{55} \mathrm{~N}_{9} \mathrm{O}_{7}$ and a molecular weight of $882.02 .{ }^{5,7}$

Literature survey reveals that only one method was developed for quantification of Elbasvir in rat plasma by using LC-MS/MS. ${ }^{8}$ There is no method reported for quantification of Elbasvir and Grazoprevir by using LC-MS/MS in human plasma. It is important to develop a good bio analytical method with proper deuterated or analogue based internal standards interms of matrix effect and reproducibility.

The main goal of the present study is to develop and validate the novel simple, sensitive, selective, rapid, rugged and reproducible analytical method for quantitative determination of Elbasvir and Grazoprevir in human plasma by LC-MS/MS with a small amount of sample volume. Moreover, it should be a simple extraction method, which is highly sensitive, and has good linearity with a small amount of plasma usage. ${ }^{9}$

\section{MATERIALS AND METHODS}

\section{Chemicals and reagents}

The drugs grazoprevir (GP) and grazoprevir d9 (GPd9), elbasvir (ES) and elbasvir d6 (ESd6) were procured as a gift samples from Symed labs, Hyderabad, India and Toronto research chemicals, Canada. Ethyl acetate, HPLC grade methanol and acetonitrile were purchased from J.T. Baker USA. Sodium dihydrogen phosphate $\left(\mathrm{NaH}_{2} \mathrm{PO}_{4}\right.$, reagent grade), ammonium acetate (reagent grade) was purchased from Merck Limited, Worli, Mumbai. Human plasma was obtained from Doctors labs, Hyderabad, India. Ultra pure water from MilliQsystem (Millipore) was used throughout the study.

\section{Instrumentation}

The 1200 Series HPLC system (Agilent Technologies, Waldbronn, Germany) was used. Mass spectrometric detection was performed on an API 4000 triple quadrupole instrument (ABI-SCIEX, Toronto, Canada) using MRM. A turbo electrospray interface in positive ionization mode was used. Data processing was performed on Analyst 1.4.1 software package (SCIEX).

\section{Detection}

The mass transitions were selected as $m / z$. $767.3 / 553.2$, 883.4/656.3 and $m / z$ 776.4/563.3, 888.4/662.3 for quantification of GP, ES and GPd9, ESd6 respectively.

\section{Chromatographic and mass spectrometric conditions}

Agilent TC-C18, $4.6 \times 75$ mm, $3.5 \mu \mathrm{m}, 80 \AA$ column, and $5 \mathrm{mM}$ ammonium acetate: acetonitrile $(20: 80 \mathrm{v} / \mathrm{v})$ mobile phase with a flow-rate of $0.5 \mathrm{ml} / \mathrm{min}$ was used. The column was placed at a temperature of $40^{\circ} \mathrm{C} .20 \mathrm{~L}$ of sample was injected into LC-MS/MS System. The analytes and internal standards were eluted at 1.62 mins (GP), 0.56 mins (GPd9) and 1.94 mins (ES), 1.93 minutes (ESd6) with total runtime of 4 mins for each injection.

\section{Calibration standards and quality control Samples}

Standard Stock solutions of GP $(100.0 \mu \mathrm{g} / \mathrm{ml})$, GPd9 $(100.0 \mu \mathrm{g} / \mathrm{ml})$, ES $(100.0 \mu \mathrm{g} / \mathrm{ml})$, ESd6 $(100.0 \mu \mathrm{g} / \mathrm{ml})$ were prepared in methanol. From each stock solution $100.0 \mathrm{ng} / \mathrm{ml}$ intermediate dilution was prepared in plasma. Aliquots of $100.0 \mathrm{ng} / \mathrm{ml}$ were used to spike blank human plasma in order to obtain calibration curve standards of 50.0, 100.0, 500.0, 1000.0, 2000.0, 4000.0, $6000.0,8000.0,10000.0 \mathrm{pg} / \mathrm{ml}$. Four levels of QC concentrations at 50.0, 150.0, 3000.0 and $7000.0 \mathrm{pg} / \mathrm{ml}$ (LLOQ, LQC, MQC and HQC) were prepared by using the different plasma. Spiked calibration curve standards and Quality control standards were stored at $-30^{\circ} \mathrm{C}$. Standard stock solutions of GPd9, ESd6 (100.0 $\mu \mathrm{g} / \mathrm{ml})$ were prepared in methanol. GPd9 and ESd6 was further diluted to $10.0 \mathrm{ng} / \mathrm{ml}$ (Spiked concentration of internal standard) using 50\% methanol and was stored in the refrigerator at a temperature of $2-8^{\circ} \mathrm{C}$ until analysis.

\section{Sample preparation}

Liquid-liquid extraction was carried out to extract the drug and internal standard. For this purpose, $100 \mu \mathrm{l}$ of respective concentration of plasma sample was taken into polypropylene tubes and mixed with $50 \mu \mathrm{l}$ of internal standard $(10.0 \mathrm{ng} / \mathrm{ml})$. This was followed by addition of 1001 of $5 \mathrm{mM} \mathrm{NaH}_{2} \mathrm{PO} 4$ solution and $3.0 \mathrm{ml}$ of ethyl acetate and vortexed for approximately 10 mins. Then the samples were centrifuged at $4000 \mathrm{rpm}$ for 10 minutes at $20^{\circ} \mathrm{C}$. Further, the supernatant was transferred into labeled polypropylene tubes and evaporated with nitrogen gas at $40^{\circ} \mathrm{C}$. Then the samples were reconstituted with the mobile phase and vortexed for 2 mins. Finally, Sample was transferred into auto sampler vials to inject into the LC-MS/MS. 


\section{Selectivity and specificity}

Selectivity was performed by analyzing the human blank plasma samples from six different sources (donors) to test for interference at the retention times of analytes. The peak area of GP and ES in blank samples should not be more than $20 \%$ of mean peak area of LOQ of GP and ES. Similarly, peak area of GPd9 and ESd6 in a blank sample should not be more than $5 \%$ of mean peak area of LOQ of GPd9 and ESd6.

\section{Precision and accuracy}

Precision and accuracy was determined by replicate analysis of quality control samples $(n=6)$ at LQC (low quality control), MQC (medium quality control) and HQC (high quality control) levels. The \% CV should be less than 15\%, and accuracy should be within 15\% except LLOQ where it should be within $20 \%$.

\section{Matrix effect}

The matrix effect due to plasma was used to evaluate the ion suppression/enhancement in a signal when comparing the absolute response of QC samples after pretreatment (Liquid-liquid extraction with ethyl acetate) with that of the reconstituted samples. Experiments were performed at MQC levels in triplicate with six different plasma lots. The acceptable precision $(\% \mathrm{CV})$ of $\leq 15 \%$ was maintained.

\section{Recovery}

The extraction efficiencies of GP, ES and GPd9, ESd6 were determined by analysis of six replicates at each quality control concentration level for GP and ES and at one concentration for the internal standard GPd9 and ESd6. The per cent recovery was evaluated by comparing the peak areas of extracted standards to the peak areas of non extracted standards (spiked into mobile phase).

\section{Limit of detection and quantification (LOD and LOQ)}

The limit of detection (LOD) is a parameter that provides the lowest concentration in a sample that can be detected from background noise but not quantitated. LOD was determined using the signal-to-noise ratio $(\mathrm{s} / \mathrm{n})$ of $3: 1$ by comparing test results from samples with known concentrations of analytes with blank samples.

The limit of quantitation (LOQ) is defined as the lowest concentration of analyte that can be determined with acceptable precision and accuracy. The LOQ was found by analyzing a set of mobile phase and plasma standards with a known concentration of GP and ES.

\section{Stability (Freeze- thaw, Auto sampler, Room temperature, Long term)}

Stock solution stability was performed by comparing the area response of analyte and internal standard in the stability sample, with the area response of sample prepared from fresh stock solution.

Stability studies in plasma were performed at the LQC and HQC concentration level using six replicates at each level. Analyte was considered stable if the \% Change is less than $15 \%$ as per US FDA guidelines. The stability of spiked human plasma samples stored at room temperature (bench top stability) was evaluated for $61 \mathrm{~h}$. The stability of spiked human plasma samples stored at $-30^{\circ} \mathrm{C}$ in autosampler (autosampler stability) was evaluated for $70 \mathrm{~h}$. The autosampler sample stability was evaluated by comparing the extracted plasma samples that were injected immediately (time $0 \mathrm{~h}$ ), with the samples that were reinjected after storing in the autosampler at $20^{\circ} \mathrm{C}$ for $70 \mathrm{~h}$. The reinjection reproducibility was evaluated by comparing the extracted plasma samples that were injected immediately (time $0 \mathrm{~h}$ ), with the samples that were re-injected after storing in the autosampler at $20^{\circ} \mathrm{C}$ for $70 \mathrm{~h}$. The freeze-thaw stability was conducted by comparing the stability samples that had been frozen at $-30^{\circ} \mathrm{C}$ and thawed three times, with freshly spiked quality control samples. Six aliquots each of LQC and HQC concentration levels were used for the freeze-thaw stability evaluation. For long term stability evaluation the concentrations obtained after 91 days were compared with initial concentrations.

\section{RESULTS AND DISCUSSION}

\section{Method development and validation}

The goal of this work is to develop and validate a simple, rapid and sensitive assay method for the quantitative determination of GP, ES from plasma samples. LC-MS/ MS has been used as one of the most powerful analytical tools in clinical pharmacokinetics for its selectivity, sensitivity and reproducibility. The MS optimization was performed by direct infusion of solutions of GP, ES, GPd9 and ESd6 into the ESI source of the mass spectrometer. The vital parameters like ionization type, temperature, voltage, gas parameters such as nebulizer and heater gases, compound parameters like DP, EP, FP, $\mathrm{CE}$ and CXP were optimized to obtain a better spray shape and ionization to form the respective productions from the protonated GP, ES, GPd 9 and ESd6 molecules (Figure 2 and Figure 3). Chromatographic conditions, especially, composition of the mobile phase, selection of suitable column were optimized through several trials to achieve the best resolution and increase the 


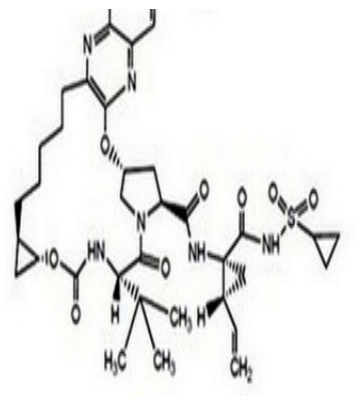

Grapopereir

Figure 1: Chemical structures of Grazoprevir and Elbasvir.

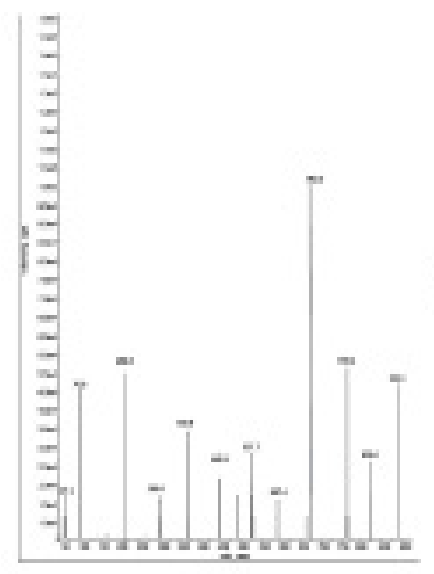

Fhar

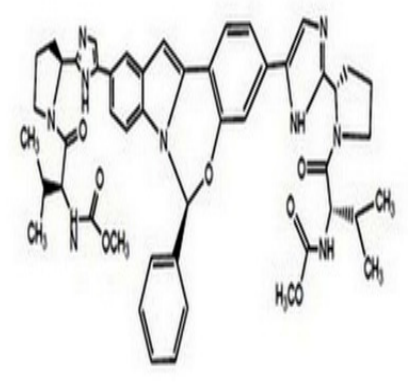

Ellossiri
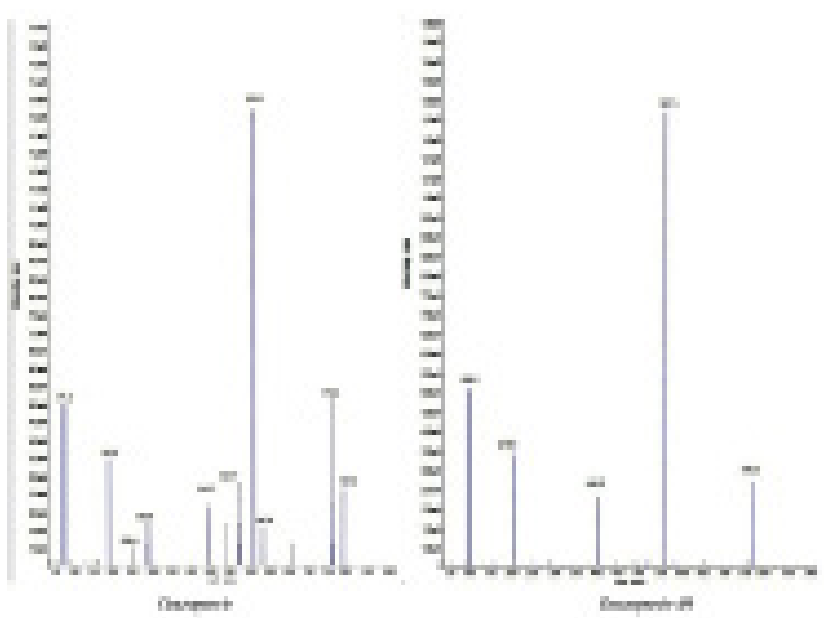

Figure 2: Product ion mass spectrum of Grazoprevir and Grazoprevir-d9.
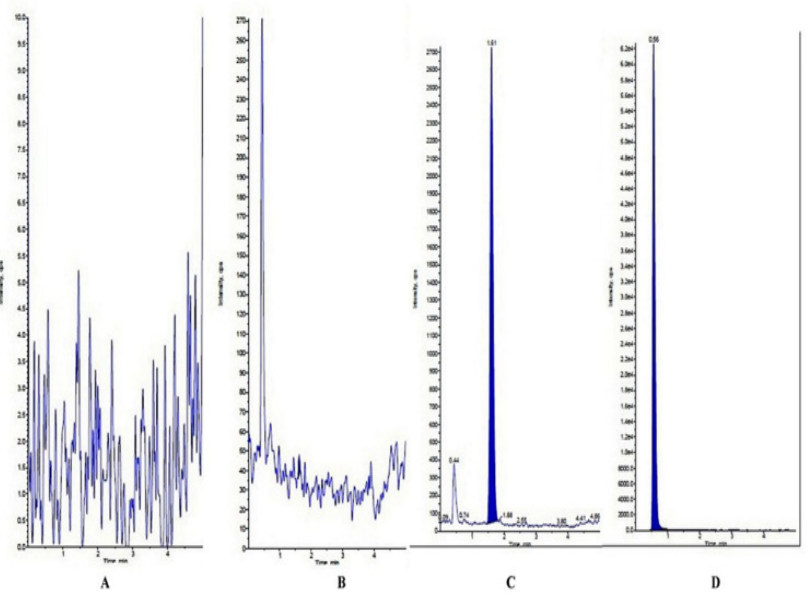

Figure 4: Typical MRM chromatograms. A and B:Blank chromatograms of grazoprevir, grazoprevir-d9; C and D: Grazoprevir in plasma spiked with grazoprevir-d9.
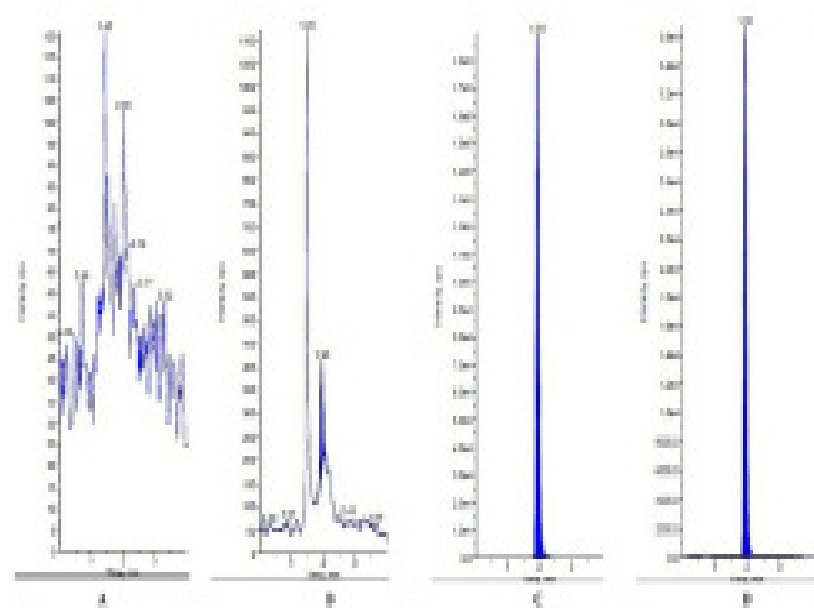

Figure 5: Typical MRM chromatograms. A and B:Blank chromatograms of Elbasvir and Elbasvir-d6; $C$ and D: Elbasvir in plasma spiked with Elbasvir-d6. 


\begin{tabular}{|c|c|c|c|c|}
\hline \multicolumn{5}{|c|}{ Table 1: Calibration curve details of grazoprevir and elbasvir } \\
\hline $\begin{array}{c}\text { Spiked plasma } \\
\text { concentration }(\mathbf{p g} / \\
\mathbf{m l})\end{array}$ & $\begin{array}{c}\text { Concentration } \\
\text { measured(mean) }(\mathbf{p g} / \\
\mathbf{m l}),(\boldsymbol{n}=\mathbf{5})\end{array}$ & $\begin{array}{c}\text { Precision } \\
(\mathbf{C V} \%) \\
(\boldsymbol{n}=\mathbf{5})\end{array}$ & $\begin{array}{c}\text { Concentration } \\
\text { measured(mean) (pg/ } \\
\mathbf{m l}),(\boldsymbol{n}=\mathbf{5})\end{array}$ & $\begin{array}{c}\text { Precision } \\
(\mathbf{C V} \%) \\
(\boldsymbol{n}=\mathbf{5})\end{array}$ \\
\hline & \multicolumn{2}{|c|}{ Grazoprevir } & & \multicolumn{2}{c|}{ Elbasvir } \\
\hline 50.0 & $51.0 \pm 1.3$ & 2.5 & $51.2 \pm 1.0$ & 2.0 \\
\hline 100.0 & $96.6 \pm 4.7$ & 4.9 & $95.8 \pm 3.4$ & 3.5 \\
\hline 500.0 & $498.4 \pm 24.7$ & 5.0 & $495.1 \pm 26.3$ & 5.3 \\
\hline 1000.0 & $1000.0 \pm 17.1$ & 1.7 & $1010.5 \pm 28.3$ & 2.8 \\
\hline 2000.0 & $2013.0 \pm 74.6$ & 3.7 & $2019.1 \pm 70.0$ & 3.5 \\
\hline 4000.0 & $4008.4 \pm 206.6$ & 5.2 & $4067.1 \pm 224.9$ & 5.5 \\
\hline 6000.0 & $5956.5 \pm 190.7$ & 3.2 & $5628.5 \pm 735.7$ & 13.1 \\
\hline 8000.0 & $7952.2 \pm 165.6$ & 2.1 & $8162.8 \pm 191.2$ & 2.3 \\
\hline 10000.0 & $10317.1 \pm 487.6$ & 4.7 & $10440.0 \pm 521.5$ & 5.0 \\
\hline
\end{tabular}

\begin{tabular}{|c|c|c|c|c|c|c|}
\hline \multicolumn{7}{|c|}{ Grazoprevir } \\
\hline \multirow[b]{2}{*}{$\begin{array}{l}\text { Spiked plasma } \\
\text { concentration } \\
(\mathrm{pg} / \mathrm{ml})\end{array}$} & \multicolumn{3}{|c|}{ Within-run $(n=6)$} & \multicolumn{3}{|c|}{ Between-run $(n=30)$} \\
\hline & $\begin{array}{c}\text { Concentration } \\
\text { measured }(\mathrm{pg} / \mathrm{ml}) \\
(\text { mean } \pm \text { S.D.) }\end{array}$ & $\begin{array}{l}\text { Precision } \\
\text { (CV \%) }\end{array}$ & $\begin{array}{c}\text { Accuracy } \\
\%\end{array}$ & $\begin{array}{c}\text { Concentration } \\
\text { measured } \\
\text { (pg/ml) (mean } \pm \\
\text { S.D.) }\end{array}$ & $\begin{array}{c}\text { Precision } \\
\text { (CV \%) }\end{array}$ & $\begin{array}{c}\text { Accuracy } \\
\%\end{array}$ \\
\hline 50.0 & $51.4 \pm 2.3$ & 4.5 & 102.7 & $55.5 \pm 4.1$ & 7.4 & 110.6 \\
\hline 150.0 & $152.9 \pm 1.4$ & 2.2 & 105.5 & $151.9 \pm 1.7$ & 1.6 & 102.2 \\
\hline 3000.0 & $3103.8 \pm 102.0$ & 3.3 & 103.2 & $3133.0 \pm 108.2$ & 3.5 & 104.3 \\
\hline 7000.0 & $7197.1 \pm 89.9$ & 1.2 & 91.7 & $7178.7 \pm 275.5$ & 1.8 & 103.9 \\
\hline \multicolumn{7}{|c|}{ Elbasvir } \\
\hline 50.0 & $42.4 \pm 1.0$ & 2.4 & 84.8 & $49.9 \pm 6.9$ & 3.8 & 99.4 \\
\hline 150.0 & $152.6 \pm 2.3$ & 1.4 & 106.4 & $151.5 \pm 1.6$ & 1.2 & 101.6 \\
\hline 3000.0 & $3072.4 \pm 132.6$ & 4.3 & 102.4 & $3216.1 \pm 162.6$ & 5.1 & 107.1 \\
\hline 7000.0 & $7160.1 \pm 105.8$ & 1.4 & 98.0 & $7174.3 \pm 123.9$ & 1.1 & 102.1 \\
\hline
\end{tabular}

\begin{tabular}{|c|c|c|c|c|c|}
\hline Stability experiments & $\begin{array}{l}\text { Storage } \\
\text { condition }\end{array}$ & $\begin{array}{c}\text { Spiked plasma } \\
\text { concentration (pg/ } \\
\mathrm{ml})\end{array}$ & $\begin{array}{c}\begin{array}{c}\text { Concentration } \\
\text { measured } \\
(n=6)\end{array} \\
\text { Mean } \pm S D\end{array}$ & $\begin{array}{c}\mathrm{CV}(\%) \\
(n=6)\end{array}$ & $\begin{array}{c}\text { Accuracy } \\
(\%)\end{array}$ \\
\hline \multicolumn{6}{|c|}{ Grazoprevir } \\
\hline \multirow{2}{*}{$\begin{array}{c}\text { Bench top } \\
\text { (Room temperature) }\end{array}$} & \multirow{2}{*}{$\begin{array}{l}\mathrm{RT} \\
61 \mathrm{hr}\end{array}$} & 150.0 & $148.3 \pm 8.1$ & 5.5 & 98.9 \\
\hline & & 7000.0 & $6728.3 \pm 206.3$ & 3.1 & 81.5 \\
\hline \multirow{2}{*}{$\begin{array}{c}\text { Processed } \\
\text { (extracted sample) }\end{array}$} & \multirow{2}{*}{$\begin{array}{l}\text { Auto sampler } \\
70 \mathrm{hr}\end{array}$} & 150.0 & $162.3 \pm 2.4$ & 1.5 & 108.2 \\
\hline & & 7000.0 & $7536.7 \pm 294.5$ & 3.9 & 90.4 \\
\hline \multirow{2}{*}{ Freeze \& Thaw stability } & \multirow{2}{*}{$\begin{array}{c}-30^{\circ} \mathrm{C} \\
\text { Cycle-3 }\end{array}$} & 150.0 & $156.5 \pm 4.0$ & 2.5 & 104.3 \\
\hline & & 7000.0 & $7381.7 \pm 173.4$ & 2.3 & 90.4 \\
\hline \multirow{2}{*}{ Long term stability } & \multirow[t]{2}{*}{$-30^{\circ} \mathrm{C}, 91$ days } & 50.0 & $160.3 \pm 13.2$ & 8.2 & 106.9 \\
\hline & & 7000.0 & $7450.0 \pm 229.1$ & 3.1 & 90.5 \\
\hline \multicolumn{6}{|c|}{ Elbasvir } \\
\hline \multirow{2}{*}{$\begin{array}{c}\text { Bench top } \\
\text { (Room temperature) }\end{array}$} & \multirow{2}{*}{$\begin{array}{l}\mathrm{RT} \\
61 \mathrm{hr}\end{array}$} & 150.0 & $156.3 \pm 8.7$ & 5.6 & 104.2 \\
\hline & & 7000.0 & $7411.7 \pm 213.7$ & 2.9 & 92.6 \\
\hline \multirow{2}{*}{$\begin{array}{c}\text { Processed } \\
\text { (extracted sample) }\end{array}$} & \multirow{2}{*}{$\begin{array}{l}\text { Auto sampler } \\
70 \mathrm{hr}\end{array}$} & 150.0 & $161.7 \pm 4.9$ & 3.0 & 107.8 \\
\hline & & 7000.0 & $7675.0 \pm 473.5$ & 6.2 & 95.9 \\
\hline \multirow{2}{*}{ Freeze \& Thaw stability } & \multirow{2}{*}{$\begin{array}{c}-30^{\circ} \mathrm{C} \\
\text { Cycle-3 }\end{array}$} & 150.0 & $159.7 \pm 7.6$ & 4.7 & 106.4 \\
\hline & & 7000.0 & $7540.0 \pm 323.0$ & 4.3 & 94.3 \\
\hline \multirow{2}{*}{ Long term stability } & \multirow{2}{*}{$-30^{\circ} \mathrm{C}, 91$ days } & 50.0 & $159.0 \pm 6.3$ & 4.0 & 106.0 \\
\hline & & 7000.0 & $7608.3 \pm 297.2$ & 3.9 & 95.1 \\
\hline
\end{tabular}


signal of analyte and internal standard. Different extraction methods like solid phase extraction, Liquid-liquid extraction, precipitation methods were optimized for extraction of GP, ES, GPd9 and ESd6 from the plasma sample. A good separation and elution were achieved using $5 \mathrm{mM}$ ammonium acetate: acetonitrile $(20: 80 \mathrm{v} / \mathrm{v})$ as the mobile phase, at a flow-rate of $0.5 \mathrm{ml} / \mathrm{min}$ and injection volume of $20 \mu \mathrm{L}$. Liquid-liquid extraction was chosen to optimize the drug and internal standard. The retention time was optimized 1.62 mins (GP), 0.56 mins (GPd9) and 1.94 mins (ES), 1.93 mins (ESd6) (Figure 4 and Figure 5).

\section{Linearity}

Calibration curve was plotted as the peak area ratio (GP/GPd9 and ES/ESd6) versus (GP and ES) concentration. Calibration was found to be linear over the concentration range of $50.0-10000.0 \mathrm{pg} / \mathrm{ml}$. The correlation coefficient $\left(\mathrm{r}^{2}\right)$ was greater than 0.9997 for all curves (Table 1).

\section{Selectivity}

The selectivity of the method was assessed by comparing chromatograms of blank plasma. There were no significant endogenous peaks at respective retention time of GP, ES, GPd9, ESd6. The results indicate that the method exhibited both good specificity and selectivity (Figure 4 and Figure 5).

\section{Precision and Accuracy}

Precision and accuracy for this method were controlled by calculating the Within-run and Between-run variations at three concentrations $(150.0,3000.0$ and $7000.0 \mathrm{pg} / \mathrm{ml}$ ) of QC samples in six replicates. As shown in Table 2, the Within-run precision and accuracy were between 1.2 to 4.5 and 91.7 to $105.5 \%$ for GP, 1.4 to 4.3 and 84.8 to $106.4 \%$ for ES. Similarly, the Between-run precision and accuracy were between 1.6 to 7.4 and 102.2 to $110.6 \%$ for GP, 1.1 to 5.1 and 99.4 to $107.1 \%$ for ES. These results indicate the adequate reliability and reproducibility of this method within the analytical range (Table 2).

\section{Matrix effect}

The ion suppression/enhancement in the signal at MQC level was found \%CV 1.27 for GP and \%CV 1.20 for ES respectively. These results indicate that there is no effect on ion suppression and ion enhancement.

\section{Recovery}

The extraction recoveries of GP were determined at three different concentrations 150.0, 3000.0 and 7000.0 $\mathrm{pg} / \mathrm{ml}$, were found to be $99.6 \pm 3.53,88.2 \pm 2.7$ and $97.60 \pm 4.7 \%$. Similarly, extraction recoveries of ES were determined at three different concentrations 150.0, 3000.0 and $7000.0 \mathrm{pg} / \mathrm{ml}$, were found to be $95.5 \pm$ 9.7, $92.6 \pm 10.21$ and $92.3 \pm 4.7 \%$. The overall average recoveries of GP, ES, GPd9 and ESd6 was found to be $95.1 \pm 6.1,93.5 \pm 1.8,96.0 \pm 2.8$ and $98.1 \pm 4.47 \%$. Recoveries of the analyte and internal standard were consistent, precise and reproducible.

\section{Limits of Detection and Quantification (LOD\&LOQ)}

The LOQ signal-to-noise $(\mathrm{S} / \mathrm{N})$ values found for six injections of GP, ES at LOQ concentration was 31.95 $\mathrm{pg} / \mathrm{ml}, 40.23 \mathrm{pg} / \mathrm{ml}$ and LOD $2.7 \mathrm{pg} / \mathrm{ml}$ and $5.4 \mathrm{pg} / \mathrm{ml}$.

\section{Stability (Freeze - thaw, Auto sampler, Room temperature, Long term)}

Stock solution stability was performed to check stability of GP, ES, GPd 9 and ESd6 in stock solutions prepared in methanol and stored at $2-8^{\circ} \mathrm{C}$ in a refrigerator. The freshly prepared stock solutions were compared with stock solutions prepared before 25 days. The $\%$ change for GP, ES, GPd 9 and ESd6 were - $0.02 \%, 0.01 \%, 0.02 \%$ and $0.03 \%$ respectively indicate that stock solutions were stable at least for 25 days. Room temperature and autosampler stability for GP and ES was investigated at LQC and HQC levels. The results revealed that GP and ES were stable in plasma for at least $60 \mathrm{~h}$ at room temperature, and $70 \mathrm{~h}$ in an auto sampler. It was confirmed that repeated freezing and thawing (three cycles) of plasma samples spiked with GP and ES at LQC and HQC levels did not affect their stability. The long-term stability results also indicated that GP and ES were stable in a matrix up to 91 days at a storage temperature of $-30^{\circ} \mathrm{C}$. The results obtained from all these stability studies are tabulated in Table 3. Precision $(\% \mathrm{CV})$ is less than 5 for room temperature, long-term, freeze thaw, auto sampler stability.

\section{CONCLUSION}

The proposed research work is highly specific due to the inherent selectivity of tandem mass spectrometry and has significant advantages over other previously described methods. Quantification of grazoprevir and elbasvir were compared with respective isotope labeled internal standards. Extraction of analyte and internal standard were achieved by using LLE. Linearity range, column, mobile phase, flow rate, injection volume, plasma usage volume for analysis was improved. Hence this method has significant advantages over previously reported methods in-terms of selectivity, sensitivity, linearity, reproducibility. 


\section{ACKNOWLEDGEMENT}

The authors wish to thank the management of Gudlavalleru Engineering College, Gudlavalleru for their encouragement to carry out the research.

\section{CONFLICT OF INTEREST}

The authors have none to declare.

\section{ABBREVIATION USED}

HCV: Hepatitis C virus; LC-MS/MS: Liquid chromatography and mass spectroscopy and mass spectroscopy; ESI: Electro spray ionisation; mm: Milli meter; $\mu \mathrm{m}$ : Micro meter; mM: milli molar; $\mathbf{V} / \mathbf{V}$ : volume by volume; $\mu \mathrm{g} / \mathrm{ml}$ : Micro gram per milli liter; $\mathbf{n g} / \mathrm{ml}$ : Nano gram per milli liter; pg/mL: Pico gram per milli liter; Å: Angstrom units; ${ }^{\circ} \mathrm{C}$ : Degree centigrade; GP: Grazoprevir; GPd9: Grazoprevir d9; ES: Elbasvir; ESd6: Elbasvir d6; LLOQ: Lower limit of quantification; LQC: Limit of quantification; MQC: Medium quality, control; HQC: High quality control; QC: Quality control; LLE: Liquid liquid extraction; SD: Standard deviation; \% CV: Percentage coefficient of variation; DP: declustering potential; EP: Entrance potential; FP: Focussing potential; CE: Collisional energy; CXP: Collisional energy existing potential; MRM: Multiple reaction monitoring; IUPAC: The International Union of Pure and Applied Chemistry.

\section{REFERENCES}

1. Perz JF, Armstrong GL, Farrington LA, Hutin YJ, Bell BP. The contributions of hepatitis $B$ virus and hepatitis $C$ virus infections to cirrhosis and primary liver cancer worldwide. Journal of Hepatology. 2006;45(4):529-38. http://dx.doi. org/10.1016/j.jhep.2006.05.013 ; PMID: 16879891.

2. Hanafiah MK, Groeger J, Flaxman AD, Wiersma ST. Global epidemiology of hepatitis $C$ virus infection: new estimates of age-specific antibody to HCV seroprevalence. Hepatology. 2013;57(4):1333-42. http://dx.doi.org/10.1002/ hep.26141; PMID: 23172780.

3. Sulkowski M, Hezode C, Gerstoft J, Vierling JM, Mallolas J, Pol S et al. Efficacy and safety of 8 weeks versus 12 weeks of treatment with grazoprevir (MK-5172) and elbasvir (MK-8742) with or without ribavirin in patients with hepatitis $C$ virus genotype 1 mono-infection and HIV/hepatitis $C$ virus co-infection (C-WORTHY): a randomized, open-label phase 2 trial. Lancet. 2015;385(9973):1087-97. http://dx.doi.org/10.1016/S0140-6736(14)61793-1; PMID: 25467560.

4. Business wire official web site. [Online].; 2016 [cited 2016 January 28 Available from: http://www.businesswire.com/news/home/20160128006608/en/ Merck-Receives-FDA-Approval-ZEPATIER\%E2\%84\%A2-elbasvir-grazoprevir.

5. Rockstroh JK, Nelson M, Katlama C, Lalezari J, Mallolas J, Bloch M et al. Efficacy and safety of grazoprevir (MK-5172) and elbasvir (MK8742) in patients with hepatitis $C$ virus and HIV co-infection (C-EDGE CO-INFECTION): a non-randomized, open-label trial. The Lancet HIV. 2015;2(8):e319-27. http://dx.doi.org/10.1016/S2352-3018(15)00114-9; PMID: 26423374.

6. Coburn CA, Meinke PT, Chang W, Fandozzi CM, Graham DJ, Hu B, et al. Discovery of MK-8742: an HCV NS5A inhibitor with broad genotype activity. Chem Med Chem. 2013;8(12):1930-40. http://dx.doi.org/10.1002/ cmdc.201300343 ; PMID: 24127258.

7. Liu R, Curry S, McMonagle P, Yeh WW, Ludmerer SW, Jumes PA, et al. Susceptibilities of genotype $1 \mathrm{a}, 1 \mathrm{~b}$, and 3 hepatitis $C$ virus variants to the NS5A inhibitor elbasvir. Antimicrobial Agents and Chemotherapy. 2015;59(11):6922-9. http://dx.doi.org/10.1128/AAC.01390-15; PMID: 26303801; PMCID: PMC4604396.

8. Liu H, Xu H, Song W, Zhang Y, Yu S, Huang X. Validated UPLC/MS/MS assay for quantitative bioanalysis of elbasvir in rat plasma and application to pharmacokinetic study. Journal of Chromatography B Analytical Technologies in the Biomedical and Life Sciences. 2016;1015(1016):150-6. http://dx.doi. org/10.1016/j.jchromb.2016.02.025; PMID: 26927874.

9. Guidance for industry: bioanalytical method validation, U.S. Department of health and human services, food and drug administration, center for drug evaluation and research (CDER), Center for biologics evaluation and research (CBER), May 2001.

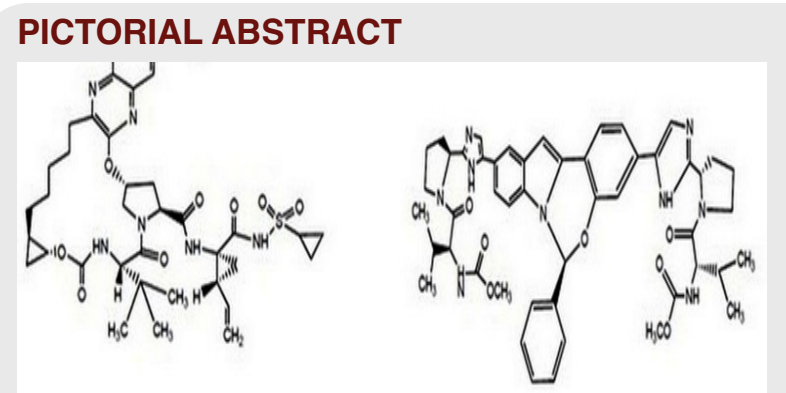

Grazoprevir

\section{SUMMARY}

- The method described in this manuscript has been developed and validated over the concentration range of $50.0-10000.0 \mathrm{pg} / \mathrm{ml}$ in human plasma.

- The intra-batch precision was less than $15.0 \%$ and Accuracy ranged from 91.7 to $105.5 \%$ for Grazoprevir and 84.8 to $106.4 \%$ for Elbasvir.

- The inter-batch precision was less than $15.0 \%$ and Accuracy ranged from 102.2 to $110.6 \%$ for Grazoprevir, 1.1 to 5.1 and 99.4 to $107.1 \%$ for Elbasvir.

- The method used in the present study is easy and fast to perform; it is also characterized with an adequate accuracy, precision, selectivity and stability.

- The simplicity of the method, and using rapid liquidliquid extraction and sample turnover rate of $5.0 \mathrm{~min}$ per sample, make it an attractive procedure in highthroughput bioanalysis of Grazoprevir and Elbasvir. 


\section{About Authors}

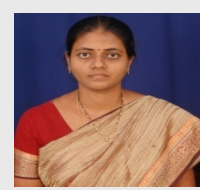

Haritha Potluri: She is working as an Assistant Professor of Chemistry in the department of BS\&H at Gudlavalleru Engineering College, Gudlavalleru, Andhra Pradesh. She has been in the teaching profession for the past 16 years. Currently, she is pursuing her Ph.D degree from JNTUK, Kakinada.

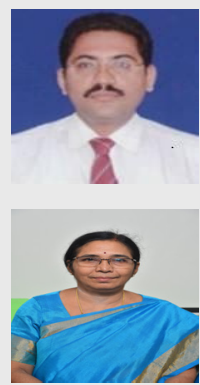

Dr. Battula Sreenivasa Rao: He is working as an Associate Professor in the department of Chemistry, GITAM University, Visakhapatnam, Andhra Pradesh since 2000. He has published 71 research papers in reputed journals. His areas of research interest are Analytical and Inorganic chemistry.

Dr. Y.Sunandamma: She is working as a Senior Assistant Professor in the department of Chemistry, Acharya Nagarjuna University, Nagarjuna Nagar, Andhra Pradesh. She has been in the teaching profession for the past 30 years. Her areas of research interest are Organometallic complexes, Doped amino acid crystals and Analytical chemistry. 